Volume: 12 Issue: 1 Year: 2015

\title{
Media exposure and influence of female athlete body images
}

\begin{abstract}
The job of any form of media is to convey a message. These messages can range from a benign sales ad to deeper subliminal message of acceptable behavior. Historically, media has taught us that men are supposed to compete in physical activities such as sport and any women who choose to do so are type casted as being lesbian or tomboys. To combat this, females often go to great lengths, including portraying themselves as sexual objects, to prove their femininity and thus lose their credibility as athletes. The other issue that can arise from this include other female athletes concentrating more on the physique of their bodies and less on performing their athletic talents.
\end{abstract}

Jeney Christensen ${ }^{1}$ Joe Deutsch ${ }^{2}$

Keywords: Body Image; Eating Disorders; Female Athletes, Media Influence

\section{Introduction}

In today's developed society, it is almost impossible not to be exposed to some form of media: television, radio, print, the internet, and the ever expanding medium of social media - it is all around. Along with this exposure comes the consumption of the messages it is aiming to communicate. These messages can range anywhere from a benign sales ad to deeper subliminal messages of socially acceptable behavior.

Historically, it has been taught in developed society that boys and men are expected to take part in physical activities such as sports. However, once a girl or woman expresses interest in those same masculine activities, they are type casted as being lesbians or tomboys (Harrison \& Secarea, 2010). To combat the stereotype and often negative connotations of being homosexual, most female athletes try to "emphasize [their] feminine characteristics, their sexuality, and to highlight their heterosexuality" (Harrison \& Secarea, 2010). One example of such an athlete is track star Lolo Jones, who is well known for being very attractive while also being vocal about her virginity and vow to remain so until she is married. Jones is well known

\footnotetext{
${ }^{1}$ North Dakota State University, Health, Nutrition, \& Exercise Sciences, USA, jeney.christensen@,ndsu.edu

2 Associate Professor of Physical Education, North Dakota State University, Health, Nutrition, \& Exercise Science, USA, Joe Deutsch joe.deutsch@,ndsu.edu
} 
in the track and field world and her failure to complete her heat of the hurdles competition in the 2008 Beijing Olympics was well covered in the 2012 London Olympics. Despite her being seen as a sexually attractive female athlete, her athletic prowess is still paramount in the media's coverage.

So why does this matter? The potential to be labeled as a lesbian because of athletic involvement and the expectations to be seen as a heterosexual sex object has created a dichotomy for female athletes. Being in the public eye through various forms of media - magazine covers, advertisements, television coverage of sport, etc. - takes this dichotomy and forces these female athletes to prove their worth, femininity, and heterosexuality to the entire world. In fact, many female sports stars, in their quest to be both marketable and feminine, have begun to lose their credibility as athletes. Harrison and Secarea (2010), found their college coed study participants were likely to see sexualized athletes to be homosexual, but also perceived them to be of "lower status," or less accomplished. An example is NASCAR driver Danica Patrick. Her sexual depictions in popular GoDaddy.com advertisements have established her as a definite heterosexual woman, but she is also perceived as a mediocre and sub-par driver. As Ryan Rudnansky wrote in a piece from BleacherReport.com (2011), Patrick's association with GoDaddy.com, "impedes her progress in gaining respect and mars her reputation." It seems as though no matter how successful she may be on the track, the public cannot look past her sexualized image.

By being portrayed as sexual objects in an attempt to confirm their reputation as a heterosexual woman has in turn hurt their reputation as a professional and accomplished athlete: “...findings indicate that tawdry sexualizations increase the likelihood women athletes will be perceived as gender normative, and decrease the likelihood that they will be respected as athletes" (Harrison \& Secarea, 2010). When this dichotomy is presented to young, promising female athletes who wish to pursue opportunities, they are forced to decide between wholehearted pursuit of athletic goals and the pressure to remain sexual and feminine. It is very uncommon for men in athletics to have to prove their heterosexual maleness; while it is almost essential for women to do so.

\section{Media Exposure and Influence}

Daniels (2009) explored how the media's portrayal of professional female athletes impacted adolescent female athletes. She based her study on two theoretical frameworks: sociocultural theory and objectification theory. Sociocultural theory, "holds that societal factors strongly influence the development and maintenance of body image through the construction of an appearance-oriented culture that values, emphasizes, and displays cultural ideals of beauty 
Christensen, J., \& Deutsch, J. (2015). Media exposure and influence of female athlete body images. International Journal of Human Sciences, 12(1), 480-486. doi: 10.14687/ijhs.v12i1.3138

and body shape" (p. 400). Rather than encouraging individuals to embrace their appearance for its own uniqueness and exclusivity, cultural ideals push those same persons to become a copy of an unrealistic model of beauty and perfection. Objectification theory holds that a women's view of herself has a tendency to manifest as a view from the outside. That is, women will view their bodies from a third-party perspective (Daniels, 2009). Feminist theory typically refers to this as the "male gaze" in media representation. Stemming from this is the theory of selfobjectification; conceptualized by both trait self-objectification (chronic focus on how the body looks) and state self-objectification (a temporary focus on how the body looks) (Daniels, 2009).

In the case of athletes, sociocultural theory is demonstrated in the coverage of female sports in the media. Much controversy surrounded the coverage of women's beach volleyball in the 2008 Beijing Olympic Games. The typical uniform for the sport is a bikini-styled top and bottom which leaves most of the athlete's body exposed. Of course, these women are typically in peak physical shape with defined musculature and very little body fat. Much debate circulates about whether the athletic prowess or physical appearance of these women is more celebrated in the media. Several independent bloggers explored the photographic files stored by Getty Images of women's beach volleyball which were generally of the athletes' rear ends. In turn, these bloggers replicated this photographic style using male athletes titling their work, “What if men's sports were photographed like women's beach volleyball?" The results were shocking, humorous, and even slightly uncomfortable. It is amazing how the media has normalized the sexuality associated with live action photographs of women, while sexualized live-action photographs of men are not normalized.

Billings, Angelini, and Duke (2010), studied how the coverage of women's sports differed from men's sports during the 2008 Beijing Olympics. In the authors' review of literature, they pointed out previous studies results showing sports broadcasters utilized less empowering descriptions of female athletes (Billings, 2008) and separated genders by separating "the powerful from the pretty" (Jones, Murrel, \& Jackson, 1999). In the authors' research, they analyzed how NBC employees described the successes, failures, and appearance of female and male athletes (Billings, Angelini, \& Duke, 2010). Using 16 classification categories, the researchers analyzed and coded all 74.5 hours of coverage NBC aired of the 2008 Beijing Olympics.

The difference of clock time allotted to each group was significant; over 4 hours of additional coverage was given to men's sports. The research acknowledged this could be due to the "Phelps factor" as the now legendary swimmer was aiming to achieve the most Olympic gold medals of any athlete of all time. However, other female-oriented stories were also significant 
Christensen, J., \& Deutsch, J. (2015). Media exposure and influence of female athlete body images. International Journal of Human Sciences, 12(1), 480-486. doi: 10.14687/ijhs.v12i1.3138

that year. Such stories included the women's beach volleyball duo of May-Treanor and Walsh and their 101 match and 18 tournament winning streak as well as the possible scandal of underaged girls on the Chinese women gymnastics team (Billings, Angelini, \& Duke, 2010). Even though there were noteworthy stories for both men's and women's teams, the men's sports received more coverage than the women's sports.

The first hypothesis of the study stated broadcasters would use different descriptors for men and women when describing performance and failures of the athletes. The second hypothesis stated broadcasters would use different descriptors when describing appearance and personalities of male and female athletes. It was found male athletes received more comments regarding their strength and innate ability, women receive comments about experience. Men also received comments about the size of specific portions and their body as a whole. What was most interesting about the latter finding was how those comments were often tied to "notions of perfection and innate physical abilities" (p. 18). Women received many more comments concerning concentration than men while receiving significantly fewer comments regarding intelligence and consonance (Billings, Angelini, \& Duke, 2010).

The fact that women athletes received fewer comments about their strength, intelligence, and consonance while receiving a significantly increased number of comments regarding experience and concentration seems to insinuate a female athlete can practice and compete just as much as or longer than male counterparts, but will never be as strong, smart, or poised. While one could argue this discrepancy could be used as fuel for success, it could also cause female athletes witnessing the broadcast to doubt their abilities (Christianson \& Deutsch, 2014).

This brings us back to Daniels (2009) and the second theoretical framework employed by her study: objectification theory. This theory translates to athletics in the form of athletes concentrating more on the physique of their bodies and less on performing their athletic talents to the best of their ability. The drive to be attractive may overcome their own health, safety, and even success as an elite talent in their field.

Self-objectification theory states women's bodies begin to be subject to sexual objectification as they begin to develop and change as a result of puberty. As they develop and mature, their bodies are increasingly looked at, commented on and evaluated. This increases tenfold when these young women are competing in front of spectators. In the London Olympics of 2012, many of the female athletes were ridiculed as being too "fat," despite their performance in their fields. Even all-around gold medalist gymnast, Gabby Douglas, was scorned for her "nappy 
Christensen, J., \& Deutsch, J. (2015). Media exposure and influence of female athlete body images. International Journal of Human Sciences, 12(1), 480-486. doi: 10.14687/ijhs.v12i1.3138

hair" by spectators. The perceived and socially accepted attractiveness of these athletes superseded their accomplishments in the field of athletics.

Daniels' (2009) study aimed to discover how media representations of female athletes impacted both female athletes and non-athletes. She used photographs of sexualized athletes, performing athletes, sexualized models, and non-sexualized models to gather her data. It was found that women who viewed the sexualized athlete, sexualized model, and non-sexualized model photographs would describe themselves with more beauty statements while those who viewed the performance athlete used more physicality statements to describe themselves (Daniels, 2009). Her study also found the physicality statements were more emotional and positive in tone while the beauty statements were negative.

This study is important in understanding the dynamics of female body image as it demonstrates how media representations of athletes can influence the self-objectification of an individual, even if the exposure is minimal. Daniels (2009) quotes previous researchers stating, "the sexualization of women athletes in mass media serves to reinforce patriarchal power and devalue women's athleticism” (p. 402). Exposing women to viewing their own bodies as sexual objects rather than athletic powerhouses allows those in power - generally, men - to keep the power. The less women think of themselves, the less they will try to exceed expectations.

Limiting the depictions and images of both athletes and women in sexualized ways would be immeasurably beneficial to the confidence and self-esteem of women in terms of their body shape and size. Allowing women to see other women in more powerful and active ways would break the cycle of poor body image and sexualization of female athletics.

Carty (2005), in a piece titled, "Textual Portrayals of Female Athletes: Liberation or Nuanced Forms of Patriarchy?" explored the bodies of female athletes and the contradicting messages they send to young women. Carty specifically questions how much ground female athletes can truly say they have gained when their bodies are not solely praised for strength and ability, but sexual attractiveness. The author questioned how current depictions of athletes in the media reflect the success of women's athletics in the wake of Title IX. Through radical feminist and postfeminist theoretical frameworks, the author analyzed television and print advertisements in which female athletes were represented.

Carty (2005) explains the different perspectives both radical feminists and postfeminists have regarding female athletes posing nude. Postfeminists argue posing nude is a form of empowerment and liberation for female athletes. It allows them to redefine their bodies on their own terms. They no longer are objects of sexual desire, but objects of power in their own right. Radical feminists disagree that posing nude is to be perceived as personal accomplishment for 
Christensen, J., \& Deutsch, J. (2015). Media exposure and influence of female athlete body images. International Journal of Human Sciences, 12(1), 480-486. doi: 10.14687/ijhs.v12i1.3138

female athletes. They argue that while the athlete may perceive their body and depiction as that of power and liberation, that same image must be approved by men as acceptable first; thus feeding the patriarchal notion that women's bodies are meant for men's sexual desires.

Those athletes who have posed nude typically justify their actions by claiming they are not doing so to be sexual, but in actuality wish to showcase their strength and athleticism (Carty, 2005). The inherent problem with this attitude lies with the fact these spreads were photographed and featured by magazines that have a predominantly male fan base. As Carty states, "Though nudity may be empowering for [female athletes] as individuals, this type of pose is situated perfectly within the confines of what the male gaze deems as 'appropriately feminine'."

Some athletes have perpetuated their sexual depictions to a point where they overshadow their athletic accomplishments. Carty uses Anna Kournikova - a well-known professional tennis player - as an example, "She is worth over ten million dollars in endorsements, though she has never won a major tournament. And she aggressively accentuates her sex appeal over her athletic ability" (Carty, 2005).

Between the example of Kournikova using her sexuality to advance her athletic career and Carty's explanations of accomplished female athletes' bodies being seen as objects of sexual desire regardless of intentions, what sort of messages are young female athletes receiving from their supposed role models in the media? Be a great athlete, but made sure you are attractive while doing so? These sorts of statements cannot and do not condone a healthy body image for up and coming female athletes (Christiansen \& Deutsch, 2014). Even the "strong" women like soccer stars Brandi Chastain and Hope Solo are presented as attractive, sexual beings. If a young woman does not have the same body type as these athletes, she could find herself questioning her worth as not only an athlete, but a woman as well. Rather than gauging success on her ability, athleticism, and accomplishments on the court or field, she may gauge it based upon how marketable her body is to the general public; thus perpetuating a negative body image.

\section{References}

Billings, A., Angelini, J., \& Duke, A. (2010). Gendered profiles of Olympic history: Sportscaster dialogue in the 2008 Beijing Olympics. Journal of Broadcasting \& Electronic Media, 54(1), 9-23.

Carty, V. (2005). Textual portrayals of female athletes: Liberation or nuanced forms of patriarchy?. Frontier, 26(2), 132-155.

Christensen, J. \& Deutsch, J. (2014). Body image and eating disorders, over-exercising, body dysmorphic disorder and other health concerns effecting student athletes. Education Practice and Innovation, 1(4), 70-74. 

Human Sciences, 12(1), 480-486. doi: 10.14687/ijhs.v12i1.3138

Christianson, P. \& Deutsch, J. (2012). Making a case for early sport specialization in youth athletes. Journal of Youth Sports, 6(2), 3-6.

Daniels, E. (2009). Sex objects, athletes, and sexy athletes: How media representations of women athletes can impact adolescent girls and college women. Journal of Adolescent Research, 24, 399-422.

Harrison, L. \& Secarea, A. (2010). College students' attitudes toward the sexualization of professional women athletes. Journal of Sport Behavior, 33, 404-426.

Jones, R., Murrell, A., \& Jackson, J. (1999). Pretty versus powerful in the sports pages. Journal of Sport and Social Issues, 23, 183-192.

Rudnansky, R. (2011, May 23). Danica Patrick: Sexy GoDaddy ads continue to tarnish danica's repuation. BleacherReport.com. Retrieved from http://bleacherreport.com/ articles/710014indianapolis-500-danica-patrick-indy-500-start-time-and news/entry/88817-danica-patricksexy-godaddy-ads-continue-to-tarnish-danicas- reputation 